\title{
Gamificação como aliada na Educação Empreendedora
}

\author{
Esteic Janaina Santos Batista ${ }^{1}$, Renato Massao Shiwa ${ }^{1}$, Lin Ming Feng ${ }^{1}$ \\ Instituto Federal de Mato Grosso do Sul (IFMS) \\ Caixa Postal 287 - 79909-000 - Ponta Porã - MS - Brasil \\ \{esteic.batista, renato.shiwa, lin.feng\}@ifms.edu.br
}

\begin{abstract}
This paper presents the proposal of a gamified web tool to aid in the teaching-learning of Entrepreneurship. Named InovaEdu, she assists the student in structuring and organizing dreams, creating the business model and plan, and simulating investments for the fictional business. In the application, students and teachers play roles of characters such as: investor, consultant, risk rating agency. The purpose of the tool is to make Entrepreneurship classes dynamic, fun and hands-on by developing skills such as teamwork, organization, responsibility, leadership, persistence, which are necessary not only for creating a business, but for life.
\end{abstract}

Resumo. Este trabalho apresenta a proposta de uma ferramenta web gamificada para auxílio no ensino-aprendizagem de Empreendedorismo. Nomeada como InovaEdu, ela auxilia o estudante na estruturação e organização de sonhos, criação do modelo e plano de negócio, além de simular investimentos para o negócio fictício. Na aplicação, estudantes e professores, desempenham papéis de personagens como: investidor, consultor, agência classificadora de risco. O objetivo da ferramenta é tornar as aulas de Empreendedorismo dinâmicas, divertidas e com experiências práticas, desenvolvendo habilidades como trabalho em equipe, organização, responsabilidade, liderança, persistência, que são necessárias não apenas para a criação de um negócio, mas para a vida.

\section{Introdução}

Nos últimos anos, diversas iniciativas de implantação do empreendedorismo na educação, seja como tema transversal às diversas disciplinas do currículo, seja como disciplina propriamente dita, constante do currículo de instituições educacionais formais de educação básica e superior, privadas e públicas [Souza 2012].

A educação empreendedora prepara o estudante para uma vida de liderança e protagonismo, mais do que para uma ocupação ou criação de um negócio, envolvendo diversos saberes e habilidades: saber como ser, como se tornar, como projetar e implementar atividades, como fazer, saber gerenciar, saber aprender, e saber como conviver, e ainda, saber identificar, agarrar e aproveitar oportunidades, buscando e gerenciando recursos de modo a transformar oportunidades em negócios de sucesso. Esta é a essência da Pedagogia Empreendedora, denominada por [Dolabela and Filion 2014], que concebe o empreendedorismo mais como uma forma de ser do que apenas uma forma de fazer, e foi projetada para desenvolver o potencial criativo dos estudantes.

Considerando, ainda que, as matrizes curriculares precisam fornecer uma formação mais prática com aulas participativas que engajem os estudantes sua própria 
VIII Congresso Brasileiro de Informática na Educação (CBIE 2019)

Anais do XXV Workshop de Informática na Escola (WIE 2019)

formação [Jucá and Rolim 2013], gamificou-se as aulas de Empreendedorismo da turma do sétimo período do curso Técnico em Informática Integrado ao Ensino Médio utilizando a metodologia descrita no artigo de [Jucá and ROLIM 2014] com algumas adaptações.

A gamificação consiste na utilização de elementos dos games fora do contexto dos games, com a finalidade de motivar os indivíduos à ação, auxiliar na solução de problemas e promover aprendizagens [Fardo 2013].

Este trabalho apresenta a proposta de uma ferramenta gamificada como forma de engajar e fornecer uma experiência significativa e envolvente para as aulas de Empreendedorismo, que será aplicada primeiramente, com estudantes do Ensino Médio, mas com possibilidade de aplicação no Ensino Superior.

\section{Metodologia}

\subsection{Relato de Experiência da Gamificação na disciplina de Empreendedorismo no Ensino Médio Técnico}

Aplicou-se durante um semestre letivo a gamificação no ensino de Empreendedorismo no Curso Técnico Integrado ao Nível Médio em Informática, usando o jogo relatado no trabalho de [Jucá and ROLIM 2014]. Aplicou-se o jogo para duas turmas com vinte estudantes em cada, sendo estas do mesmo curso, período e turno.

O jogo é constituído de 5 fases (ou desafios) que representam atividades na elaboração de um plano de negócio. As fases são: Identificação de uma oportunidade de negócio; Descrição da empresa, produtos e serviços, mercados e competidores; Análise do Mix de Marketing e comercialização; Análise Estratégica; e Plano Financeiro. Ao final de cada fase, um documento é produzido e entregue ao professor. Com base nesse documento, os investidores (cada estudante) avaliam cada negócio e decidem onde arriscar seu capital. O professor (no papel de agência) também avalia os documentos e com base na correção dos documentos indica qual o fator de retorno (que pode ser positivo, nulo ou negativo) dos investimentos realizados pelos estudantes [Jucá and ROLIM 2014].

\subsubsection{Adaptação do jogo}

Na adaptação prática, o jogo ficou constituído de seis fases, sendo a primeira constituída correspondente à validação e escolha de uma ideia para o negócio. Para isso, os estudantes desenvolveram um modelo de negócio no Canvas disponibilizado pelo Sebrae ${ }^{1}$. As demais fases eram referentes a: Sumário Executivo, Análise de Mercado, Plano de Marketing, Plano Operacional e Plano Financeiro, conforme divisão da estrutura do plano de negócios sugerida em [Biagio 2013].

No jogo, cada equipe de estudantes representa um negócio que concorre na bolsa de investimento por capital para tornar sua ideia real. Uma agência de recomendações de investimentos (papel realizado pelo professor) deve, baseado nos documentos liberados por cada negócio, classificar e recomendar as ideias propostas por cada negócio. Com base nessa classificação, os investidores saberão se ganham ou perdem capital investido. Os negócios mais bem classificados recebem mais pontos.

\footnotetext{
${ }^{1}$ Ferramenta do Sebrae para criar Canvas: https://www.sebraecanvas.com.
} 
VIII Congresso Brasileiro de Informática na Educação (CBIE 2019)

Anais do XXV Workshop de Informática na Escola (WIE 2019)

Cada estudante individualmente é investidor na bolsa de investimentos. Os estudantes começam com um capital igual e eles podem escolher em que negócios apostar (não obrigatoriamente no seu) e se o negócio escolhido por ele for bem recomendado pela agencia e receber muitos investimentos de outros investidores, seu retorno pode ser maior. Os estudantes podem acumular e entrar para o ranking dos melhores investidores.

O dinheiro ganho na bolsa de investimentos pode ser usado tanto para melhorar o negócio proposto, quanto para contratar consultores (outro papel do professor) para indicações de formas de melhorar o resultado de fases anteriores para ganhar melhor reputação com a agência.

O jogo é constituído de um conjunto de fases (ou desafios) que são primeiramente apresentados ao estudante. Depois, os estudantes devem executar o desafio e liberar para os demais estudantes o resultado do desafio levando em consideração o seu negócio proposto. Uma vez que todas as equipes terminaram o desafio é iniciada uma rodada de investimentos onde os estudantes podem pegar parte do capital (\$) pessoal investir na ideia que julga mais completa e trabalhada.

Cada fase tinha uma explicação do professor sobre o assunto abordado, e esta foi composta de três atividades:

- Pesquisa: onde vocês devem recolher links, artigos e materiais correspondentes ao assunto do desafio. Estes temas eram diferentes para cada equipe, e poderia estar atrelado ao mundo de investimentos. Algumas fases, a equipe tinha que apresentar para as demais o assunto pesquisado.

- Execução parcial do desafio: os estudantes deveriam entregar a parte escrita do desafio, que era a parte do Plano de Negócio da fase, como por exemplo, Plano de Marketing. As equipes podem comprar consultoria nesta atividade.

- Liberação da resposta da equipe ao desafio: é sobre esse documento (parte escrita finalizada podendo ou não ser acompanhado de apresentação do itens anteriores) que as outras equipes vão fazer apostas e a agência de recomendação vai classificar as ideias.

Para estimular o trabalho em equipe e uma competição entre equipes, a equipe perde uma porcentagem do investimento do seu negócios, bem como cada investidor individualmente, quando atrasavam, não entregavam ou entregavam incompletas as atividades propostas na fase. Após o término da fase e rodada de investimentos, era disponibilizado um ranking de investidores e negócios.

Durante a aplicação do jogo, utilizou-se as seguintes ferramentas:

- Sala de aula do Google: para disponibilizar os materiais de apoio, envio de atividades das fases e disponibilização do documento com o ranking de investidores e negócios.

- Planilhas eletrônicas: para calcular perdas e ganhos de cada rodada conforme regras do jogo, explicadas anteriormente.

\subsubsection{Feedback da aplicação do jogo}

Aplicou-se um questionário para os 40 estudantes de duas turmas do curso Técnico em Informática. A aplicação do jogo em sala de aula motivou os estudantes na disciplina de 
VIII Congresso Brasileiro de Informática na Educação (CBIE 2019)

Anais do XXV Workshop de Informática na Escola (WIE 2019)

Empreendedorismo, permitindo sair das aulas tradicionais e expositivas, permitindo que estes pensassem em uma solução real dentro da área do curso de informática. No entanto, encontramos alguns percalços listados a seguir:

- Rendimento do capital: os estudantes e professora sentiram falta de uma ferramenta que tornasse o capital variável todo dia, e não apenas no final de cada uma das fases que demorava cerca de 15 dias. Como a educação empreendedora está intimamente ligada à educação financeira, sentiu-se falta de algo mais realístico ao que acontece na bolsa e no mundo dos investimentos, que varia de um dia para outro.

- Plano Financeiro: durante as aulas utilizou-se ferramentas desenvolvidas pelo Sebrae MG, bem como seu livro de apoio. No entanto, por ser um plano de negócios desenvolvido por estudantes de ensino médio, percebeu-se que a ferramenta, para desenvolver o plano financeiro e operacional era pouco eficaz, e o material continha muitas fórmulas para cálculos que deveriam realizar, o que acaba ocupando muito tempo das aulas, o que não foi interessante nas aulas.

- Centralização de ferramentas e materiais: os alunos acabaram utilizando diversas ferramentas diferentes para executar as fases do jogos. Não encontrou-se um material que tivesse um link direto para as existentes, o que pode dificultar a aplicação destas em aula por professores. Quando há ferramentas descentralizadas, o tempo de execução da metodologia é aumentado, o que torna complicada a aplicação desta metodologia, uma vez que as disciplinas de Empreendedorismo são aulas, geralmente, de até duas horas por semana, nos cursos técnicos e superiores.

\section{Proposta de uma Ferramenta Gamificada de Empreendedorismo}

Este trabalho propõe uma ferramenta para auxiliar na aplicação da gamificação nas aulas de Empreendedorismo, nomeada como InovaEdu. A ferramenta contará com os seguintes personagens:

- Investidor: desempenhado por cada um dos estudantes, que começará com um determinado valor de capital.

- Negócio: formado por uma equipe de estudantes.

- Consultor: função desempenhada pelo sistema, que irá fornecendo materiais de ajuda para o estudante/negócio cumprir um desafio por meio de disponibilização de dicas extras.

- Agência classificadora de risco: papel compartilhado entre o professor (quando avaliar os documentos liberados de cada fase) e sistema (que irá variar a taxa de rendimento diariamente sobre o capital investido).

As seguintes funções poderão ser desempenhadas pelo estudante no sistema:

- Criar um negócio em grupo com outros estudantes vinculados à mesma turma.

- Comprar consultoria (dicas e materiais extras), utilizando seu capital pessoal ou capital da empresa (que será necessário o aceite de todos os investidores pertencentes àquele negócio).

- Ver histórico de ações realizadas no seu negócio.

- Avaliar documentos de atividades das fases de outros negócios.

- Investir seu capital em outros negócios.

- Submeter atividades e realizar os desafios da fase. 
VIII Congresso Brasileiro de Informática na Educação (CBIE 2019)

Anais do XXV Workshop de Informática na Escola (WIE 2019)

- Ver ranking.

As seguintes funções poderão ser desempenhadas pelo professor no sistema:

- Gerenciar turmas, incluindo: criar, renomear e definir um código para que seus alunos consigam de cadastrar e vincular-se à ela.

- Inserir avisos no mural da turma.

- Habilitar ou desabilitar visibilidade do ranking pelos estudantes de investidores e/ou negócios.

- Definir datas de entrega de atividades e desafios dentro de cada fase.

- Avaliar e atribuir pontos aos documentos enviados das atividades e desafios.

- Definir variação e regras para a taxa de rendimento de acordo com a intenção do professor em sala de aula. Por exemplo, definir que se enviado atrasado, o negócio/investidor perde $0,01 \%$ do seu capital.

O InovaEdu fornecerá ajuda no desenvolvimento de todo o seu plano de negócio, para que os estudantes se preocupem com a estruturação do seu negócio, como por exemplo, no plano financeiro, em que o estudante irá fornecer informações necessárias para que o próprio sistema realize os cálculos.

\section{Considerações Finais}

Este trabalho, relatou a aplicação da gamificação com o jogo relatado no trabalho de [Jucá and ROLIM 2014] durante as aulas da disciplina de Empreendedorismo em um curso Técnico em Informática de Nível Médio. A partir de observações e questionário aplicado aos estudantes no término da disciplina, apresentamos diversos percalços encontrados na aplicação do jogo, que poderia ser resolvido com uma ferramenta para auxiliar o professor e estudantes.

Propomos desta forma, neste trabalho, uma ferramenta, que está em fase de estruturação e prototipação, que possa auxiliar a aplicar a gamificação nas aulas de empreendedorismo para torná-las divertidas, significativas e dinâmicas.

\section{References}

Biagio, L. A. (2013). Como elaborar o plano de negócios, volume 2. Editora Manole.

Dolabela, F. and Filion, L. J. (2014). Fazendo revolução no brasil: a introdução da pedagogia empreendedora nos estágios iniciais da educação. Revista de Empreendedorismo e Gestão de Pequenas Empresas, 2(3):134-181.

Fardo, M. L. (2013). A gamificação aplicada em ambientes de aprendizagem. RENOTE, 11(1).

Jucá, P. and Rolim, G. (2013). Gamificação na disciplina de empreendedorismo. In XXI Workshop sobre Educação em Computação (WEI) do XXXIII Congresso da Sociedade Brasileira de Computação, Maceió, Brasil, SBC, pages 444-449.

Jucá, P. M. and ROLIM, G. (2014). Aplicação da gamificação na disciplina de empreendedorismo. In XXII Workshop sobre Educação em Computação (WEI 2014).

Souza, S. A. (2012). A introdução do empreendedorismo na educação brasileira: primeiras considerações. Educação \& Linguagem, 15(26):77-94. 